\title{
Microstructural Studies of the Initial Stages of Copper Sulfide Film Growth: Influence of Humidity
}

\author{
M. J. Campin,* J. C. Barbour,** J. W. Braithwaite,** P. P. Provencio** and J. G. Zhu* \\ *Dept. of Physics, New Mexico State Univ., Las Cruces, NM 88003 \\ **Sandia National Laboratories, Albuquerque, NM 87185
}

The study of copper corrosion is important because of the widespread use of copper in a number of high-reliability applications. The industrial importance of copper coupled with its thermodynamic instability in most terrestrial environments has created a need to understand the key mechanisms of copper corrosion in order to enable the prediction of copper component lifetime in different environments. This has motivated numerous atmospheric copper corrosion studies. However, copper sulfidation is challenging to study due to the possible formation of multiple sulfide phases and complex corrosion morphologies. In this study, we have used focused ion beam (FIB) crosssectioning, scanning electron microscopy (SEM), transmission electron microscopy (TEM), high-resolution TEM (HRTEM), x-ray diffraction (XRD), and ion beam analysis to characterize the product formed when thin films of copper are exposed to a dilute (50$200 \mathrm{ppb}) \mathrm{H}_{2} \mathrm{~S}$ atmosphere at low $(0.5 \%)$ to high $(80 \%)$ relative humidity $(\mathrm{RH})$. The intent of this investigation is to examine possible structural differences in the sulfides grown at low and high humidity and correlate these differences to possible changes in sulfidation mechanisms.

An important early observation was that the $\mathrm{Cu}_{2} \mathrm{~S}$ growth rate for long times is significantly higher for sulfides formed at low RH compared to high RH. As shown in figure 1, the existence of the "parabolic" stage-II type growth at high RH implies that different diffusion mechanisms dominate at low and high $\mathrm{RH}$ or that there are morphological differences between the sulfides grown at low and high RH. Studies were performed to determine whether structural differences in the sulfides could give rise to enhanced diffusion.

One explanation for the different growth mechanisms of the $\mathrm{Cu}_{2} \mathrm{~S}$ at low and high $\mathrm{RH}$ is that the solid-state diffusion of copper depends on RH. This could occur if there is a correlation between microstructure and diffusion pathways, e.g. fast diffusion pathways along thick, defective grain boundaries. TEM analysis reveals differences in grain sizes between low and high $\mathrm{RH}$ throughout the entire thickness of the $\mathrm{Cu}_{2} \mathrm{~S}$ layer, but does not reveal any significant difference in grain size at $15^{\circ} \mathrm{C}-35^{\circ} \mathrm{C}$ for a given $\mathrm{RH}$ (figs. 2-3). Cross-section TEM shows that the grains at low RH are columnar and 75-150+ nm in size, whereas grains at high RH are equiaxed and are only $20-50 \mathrm{~nm}$ in size. TEM analysis also reveals that the high RH samples have poorly connected and voided grain boundaries, no preferential grain orientations, and show no apparent grain growth as the $\mathrm{Cu}_{2} \mathrm{~S}$ layer becomes thicker (fig. 2). In contrast, the low RH samples have abrupt grain boundaries, preferential grain orientations, and show considerable growth of grains as the $\mathrm{Cu}_{2} \mathrm{~S}$ layer becomes thicker, as indicated by grain grooving (fig. 3 ).

SEM investigation of patterned copper lines of varying widths is also being pursued. Looking at the variation in thickness of the $\mathrm{Cu}_{2} \mathrm{~S}$ across the copper line in the 
SEM (fig. 4) gives us insight into sticking coefficients of $\mathrm{H}_{2} \mathrm{~S}$ and the reaction rate constants for $\mathrm{Cu}_{2} \mathrm{~S}$ at low and high $\mathrm{RH}$.

Based on preliminary modeling of copper sulfidation we speculate that growth rate at high $\mathrm{RH}$ shows slower than parabolic growth because copper diffusion through the copper sulfide is localized. The connection between the observed $\mathrm{Cu}_{2} \mathrm{~S}$ grain morphologies and the solid-state diffusivity of $\mathrm{Cu}$ will be discussed.

General references and acknowledgements:

[1] T. E. Graedel, J. P. Franey, and G. W. Kammlott, Corrosion Science 23, 1141 (1983);

T. E. Graedel et al., J. Electrochem. Soc. 134, 1632 (1987).

[2] O. M. Magnussen and R. J. Behm, MRS Bulletin 24 (\#7), 16 (1999).

[3] S. Cassaignon, T. Pauporte, J. Guillemoles, and T. Vedel, Ionics 4 (\#5-6), 364 (1998).

[4] C. Leygraf and T. Graedel, Atmospheric Corrosion, Wiley-Interscience (2000).

[5] This work was supported by the United States Department of Energy under contract DE-AC04-94AL85000. Sandia is a multi-program laboratory operated by Sandia Corp., a Lockheed Martin Co., for the United States Department of Energy.
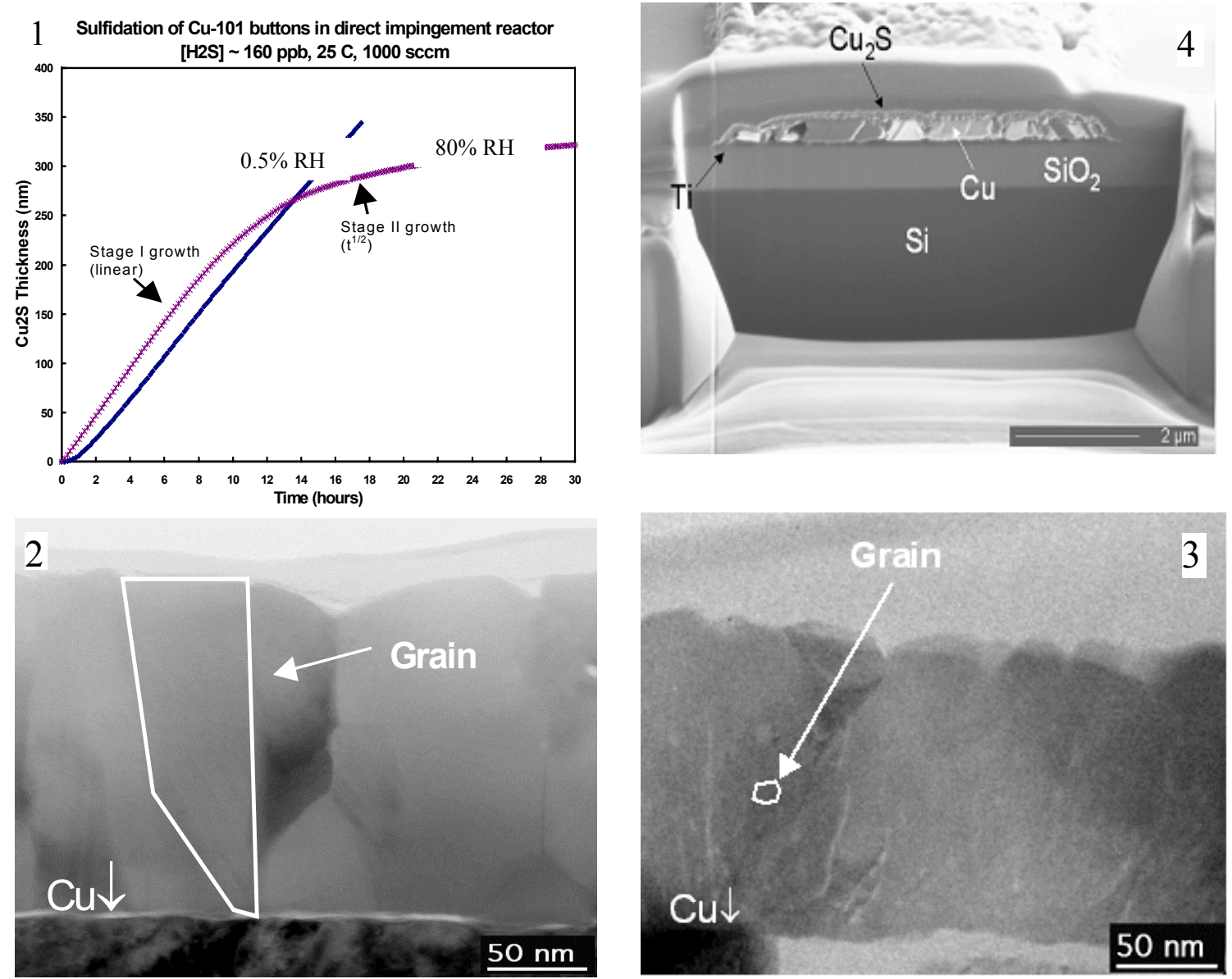

Figure 1: Plot of $\mathrm{Cu}_{2} \mathrm{~S}$ thickness vs. time.

Figure 2: Cross-sectional TEM image of sample with $\mathrm{Cu}_{2} \mathrm{~S}$ formed at $0.5 \% \mathrm{RH}$.

Figure 3: Cross-sectional TEM image of sample with $\mathrm{Cu}_{2} \mathrm{~S}$ formed at $80 \% \mathrm{RH}$.

Figure 4: SEM image of FIB cut section of a 5um copper line sulfidized at $80 \% \mathrm{RH}$. 